\title{
Physical properties and reactivity of pozzolans, and their influence on the properties of lime-pozzolan pastes
}

\author{
R. Walker · S. Pavía
}

Received: 21 April 2010/Accepted: 5 November 2010/Published online: 20 November 2010

(C) RILEM 2010

\begin{abstract}
This paper studies how pozzolan properties including particle size, specific surface, chemical and mineral composition, amorphousness and water demand, affect their reactivity as well as the strength of lime-pozzolan pastes. Reactivity was evaluated with chemical, mechanical and mineralogical methods. A number of artificial pozzolans were investigated including Ground Granulated Blastfurnace Slag (GGBS); Leca; Pulverised Fuel Ash (PFA); Calcined Clay (Metastar); Microsilica (MS); Rice Husk Ash (RHA); Red Brick Dust (RBD); Tile and Yellow Brick Dust (YBD). The paper concludes that the pozzolan's specific surface has a much greater influence on the water demand of the paste than its particle size or the lime:pozzolan ratio. It was evidenced that each pozzolan has a particular water demand for a given workability that increased with its specific surface; and that the replacement of lime by pozzolan lowers the water demand of the paste except for Metastar, on account of its greater fineness and specific surface. There is a good correlation between the chemical and physical activity indices and the rate of portlandite consumption. These evidenced that the most amorphous pozzolans (Metastar, GGBS, RHA and MS) are the most active. Finally, it also appears from the results, that the amount of lime combined by reactive
\end{abstract}

R. Walker · S. Pavía ( $\square)$

Department of Civil Engineering, Trinity College,

Dublin 2, Ireland

e-mail: pavias@tcd.ie crystalline phases in the pozzolans is insignificant when compared to that bound by their amorphous fraction. The paper concludes that amorphousness determines pozzolan reactivity to a much greater extent than any other pozzolan property. It also concludes that the specific surface area of the pozzolan governs the water demand of the paste, while amorphousness largely determines the strength of the paste. In contrast, the chemical composition of the pozzolan is not instrumental as a variable affecting neither pozzolan reactivity nor the strength of the paste.

Keywords Pozzolan - Amorphousness · Specific surface - Reactivity - Water demand · Compressive strength

\section{Introduction}

Pozzolans are materials with an amorphous siliceous or siliceous and aluminous content that react with calcium hydroxide in the presence of water to form cementitious hydration products (calcium silicate hydrates and calcium silicate aluminate hydrates).

In many ancient civilizations, pozzolans were used to enhance the properties of lime, and many structures are still extant as a testament to the durability of limepozzolan mortars and concrete. Evidence of the use of pozzolans has been found in the Neolithic period (7000 BC) in Galilee [1] referring to Malinowski et al.), 
the Minoan civilization (2700 to $1450 \mathrm{BC}$ ) [2] and Ancient Greece (1500 BC) [3] referring to Jiang and Roy. The Roman Empire is however the most synonymous with the use of pozzolans, the name deriving from the volcanic rock pozzolana, found near Naples. The Romans used both natural and artificial pozzolans such as brick and tile dust. According to historic records [4, 5, 6] and current research [7] the Romans preferred pure lime to the more hydraulic types, rendering the lime hydraulic with the addition of pozzolans. The use of lime binders decreased with the development of cements in the early nineteenth century, however, these are regaining popularity as an environmentally sustainable alternative to concrete. Their environmental credentials are based on their lower production energy consumption and the reabsorption of the $\mathrm{CO}_{2}$ emitted during burning. Artificial pozzolans are often industrial or agricultural byproducts, therefore their use with lime in construction is a better alternative than landfill disposal.

Pure lime hardens by carbonation, however the introduction of pozzolans alters the hardening process by imparting a hydraulic set. The hydration products of lime/pozzolan pastes are similar to those found in a hydraulic lime mortars and cements [8] although their formation is considerably slower than in cement pastes.

A pozzolan's activity refers to both its capacity of binding lime and the rate at which the binding reaction takes place, therefore, it covers all the reactions taking place between the active components of the pozzolan, lime and water. The reactivity of a pozzolan depends on its chemical and mineralogical composition, the type and proportion of its active phases, the particle's specific surface area, the ratio of lime to pozzolan, water content, curing time and temperature [8]. In addition, the rate of lime combination increases in the presence of sulfates such as gypsum and $\mathrm{Na}_{2} \mathrm{SO}_{4}$ and other chemicals such as $\mathrm{CaCl}_{2}$ [9]. It is widely accepted that an increase of specific area and/or decrease in particle size will expose a greater surface to chemical reaction enhancing reactivity. It is also widely accepted that amorphous structures are more reactive than crystalline ones, on account of the greater mobility and superficial location of their atoms. Glassy pozzolans with a limited amount of non-reactive, crystalline minerals are considered to be very active, while, on the contrary, weak pozzolans contain little glass and considerable amounts of crystalline minerals.
It has been proven that lime mortars with hydraulic properties display outstanding physical properties and durability both alone and when combined with masonry [10-12]. Pozzolans render lime hydraulic, therefore, they may enhance certain properties of lime mortars thus increasing their applications and potential.

This research was undertaken in order to ascertain the influence of some physical properties of pozzolans including particle size and specific surface, chemical and mineral composition, amorphousness and water demand on the pozzolan's reactivity; and how these properties affect the water demand and mechanical performance of lime-pozzolan pastes. Reactivity was evaluated with chemical methods (measuring changes in conductivity of a lime/pozzolan solution over time) as well as mechanical methods (assessing compressive strength development over time) and mineralogical methods (monitoring portlandite consumption by X-ray diffraction). It is hoped that this research will assist understanding and predicting the behavior and quality of pozzolan composites for building.

\section{Materials and methods}

\subsection{Materials}

A hydrated commercial lime (CL90s-calcium lime) complying with EN 459-1 [13] was used. Nine pozzolans were investigated including Ground Granulated Blastfurnace Slag (GGBS); Leca; Pulverised Fuel Ash (PFA); Calcined Clay (Metastar); Microsilica (MS); Rice Husk Ash (RHA); Red Brick Dust (RBD); Tile and Yellow Brick Dust (YBD). Their chemical composition is included in Table 1. Two lime:pozzolan ratios $1: 1$ and $1: 3$ (by weight) were investigated with water content to produce a flow diameter of $165 \mathrm{~mm}$ measured by the flow test.

\subsection{Chemical and mineralogical composition and amorphousness of the pozzolans}

The chemical composition was determined by XRF analysis, with a ThermoFisher Scientific and Edwards Analytical using a Quant'X EDX Spectrometer and UniQuant analysis package. An elemental quantitative analysis was carried out. The samples were 
Table 1 Specific surface area of pozzolans and fineness rating according to the laser grading results

\begin{tabular}{lll}
\hline Pozzolan & Surface area $\left(\mathrm{m}^{2} / \mathrm{g}\right)$ & Fineness rating \\
\hline MS & 23.69 & MS \\
Metastar & 18.33 & Metastar \\
RHA & 13.70 & RHA \\
RBD & 4.29 & GGBS \\
Tile & 4.16 & PFA \\
PFA & 4.09 & Leca \\
GGBS & 2.65 & Tile \\
Leca & 1.28 & RBD \\
YBD & 0.31 & YBD \\
\hline
\end{tabular}

mixed with Hoescht wax in the ratio 0.1 wax/sample, and pressed into aluminum sample cups using a hydraulic press at 10 tonnes for $60 \mathrm{~s}$.

The mineralogical composition and amorphous character of the pozzolans was analysed by X-ray diffraction (XRD), using a Phillips PW1720 XRD with a PW1050/80 goniometer and a PW3313/20 Cu K $\alpha$ anode tube at $40 \mathrm{kV}$ and $20 \mathrm{~mA}$. All measurements were taken from $3^{\circ}$ to $60^{\circ}(2 \theta)$ at a step size of $0.02^{\circ}$ s. Crystalline minerals may not be detected by XRD if their amount falls below $5 \%$ or they are concealed by other mineral peaks. The amorphous character of the pozzolan is represented on the XRD by a broad hump which that cannot be accurately measured, however the degree of amorphousness of the pozzolan is indicated by the size of the hump [14].

\subsection{Particle size and surface area of the pozzolans}

The particle size was determined using a Malvern Mastersizer 2000 based on the measurement technique of laser diffraction. The specific surface area was measured using a Quantachrome Nova 4200e and the BET method, a model isotherm based on adsorption of gas on a surface.

\subsection{Pozzolan reactivity}

Pozzolanic reactivity indicates how quickly after mixing the pozzolanic material reacts with portlandite and the rate at which the reaction takes place. In effect, it is a measure of how effective the pozzolan is. Accurately deducing a pozzolan's reactivity is complex [15] and dependant on the methodology. For this reason, the reactivity was determined using the three methods below.

\subsubsection{Early rate of pozzolanic reaction: speed of portlandite consumption}

The progress of the pozzolanic reaction was investigated by recording new-formed hydration products and changes in the relative amounts of portlandite and calcite in the XRD trace analysed as mentioned above. The relative amounts of portlandite and calcite were approximately calculated by measuring the net area under the main peak. The paste (in a lime:pozzolan ratio of 1:3) was placed directly into the XRD bulk cavity mounts in a layer approximately $2 \mathrm{~mm}$ thick. The samples were analysed at $6 \mathrm{~h}, 1$ day, 3 days, 1 week, 1 month and 4 months, and stored unsealed between testing in a curing room at $20 \pm 3^{\circ} \mathrm{C}$ and $\mathrm{RH}$ $60 \pm 10 \%$.

As the pastes cured, the portlandite was used for both carbonation (to form calcite) and pozzolanic reaction (to form hydration products). Therefore, the speed of consumption of portlandite corresponds to the early rate of pozzolanic reaction. Calcite production depends on the presence of portlandite therefore, it was assumed that, if calcite was being formed, portlandite was still available and thus the pozzolanic reaction still active.

\subsubsection{Mechanical activity index}

The mechanical method was undertaken according to EN 450-1 [16]. This measures reactivity by monitoring the compressive strength development of a lime:pozzolan mix in relation to a standard lime mix at constant water content over 28 days. The same method was applied to all pozzolans. A fixed water content was not possible as the pozzolans have different water demand, thus the same quantity of water yielded a sloppy mix with some pozzolans and a dry "breadcrumb" mix with others. Therefore, in order to determine a suitable water content, the pozzolans were mixed to flow and, according to the results obtained, they were subdivided into two groups of high and low water demand. The GGBS, Leca, PFA, RBD, Tile and YBD had a lime:pozzolan:sand:water ratio of 1:1:3:1 and therefore a binder:water ratio of 0.5 . The remaining three pozzolans: Metastar, MS and RHA, have a higher water demand 
and a ratio of 1:1:3:1.5 was selected for them. The water content was therefore fixed for the two groups. The prisms $160 \mathrm{~mm} \times 40 \mathrm{~mm} \times 40 \mathrm{~mm}$ were demoulded after 1 day and stored in a curing room at a temperature $20 \pm 3^{\circ} \mathrm{C}$ under damp hessian to maintain humidity at ca. $95 \%$. The unconfined compressive test was measured with a Zwick loading machine according to EN 459-2:2001.

\subsubsection{Chemical activity}

The chemical method followed the pozzolanic reaction indirectly by measuring the changes in the conductivity of a saturated lime and pozzolan solution. The fixation of dissolved $\mathrm{Ca}(\mathrm{OH})_{2}$ by both pozzolan particles forming hydration products and carbonation, reduce portlandite concentration in solution leading to a decrease in conductivity. A saturated solution of lime in distilled water provided an electrical conductivity reading of approx $9.8 \mathrm{mS}$ at $20^{\circ} \mathrm{C} .4 \mathrm{~g}$ of pozzolan were added to the solution. The solution was continuously stirred by a magnetic stirrer and the conductivity and temperature measured at intervals over $125 \mathrm{~h}$ using a WTW LF 197 conductivity meter with a Tetracon 325 probe. The conductivity of the pozzolan in distilled water was also measured in order to assess the pozzolan contribution to the conductivity (water soluble salt content and solubility of the pozzolans).

\subsection{Water demand of the lime/pozzolan pastes}

The water demand of the pozzolans (amount of water required to produce a specific flow value) was assessed by measuring the initial flow in accordance with EN 459-2 [17], for lime:pozzolan ratios of 1:1 and 1:3. The water content was adjusted until the sample, upon removing the mould, gave a flow a diameter of $165 \mathrm{~mm}$ after 15 jolts on the flow table. Mixing was in accordance with EN 459-2 except for sand being replaced with the pozzolan which was added after $1 \mathrm{~min}$ and the mixing stopped for $30 \mathrm{~s}$.

\section{Results and discussion}

\subsection{Physical properties and composition of pozzolans}

Particle size and specific surface are important because they affect reactivity. The particle size distribution of the pozzolans is included in Fig. 1. According to the results, the Metastar, RHA, GGBS and PFA are the finest pozzolans (finer than lime). The MS particles flocculated during the laser analysis on account of their extremely small size, therefore the MS result in Fig. 1 is not correct, and the MS is much finer than determined by the laser method. According to the producer, $60 \%$ of the MS particles are sized under $1 \mu \mathrm{m}$, therefore the MS is the finest pozzolan. The specific surface area of the pozzolans appears in Table 1. According to these results, the MS, Metastar and RHA have a much greater specific surface than any of the other pozzolans.

By comparing the particle size and surface area of the pozzolans, an indication of the shape and surface texture of their particles can be obtained. RHA and GGBS have a similar particle size however RHA has a greater surface area, this agrees with the planar geometry and smooth surface of the GGBS determined with scanning electron microscopy (SEM) (Fig. 2). Similarly, the PFA, RBD and tile have a comparable surface area and a different particle size indicating that the PFA, with the lowest particle size, has a smoother surface and/or more regular geometry than the tile and RBD. The directional shading, with the brightest particles sending a higher signal, was due to the use of back scattered in low vacuum. This further enables an easy recognition of the particle configuration.
Fig. 1 Particle size distribution of pozzolans

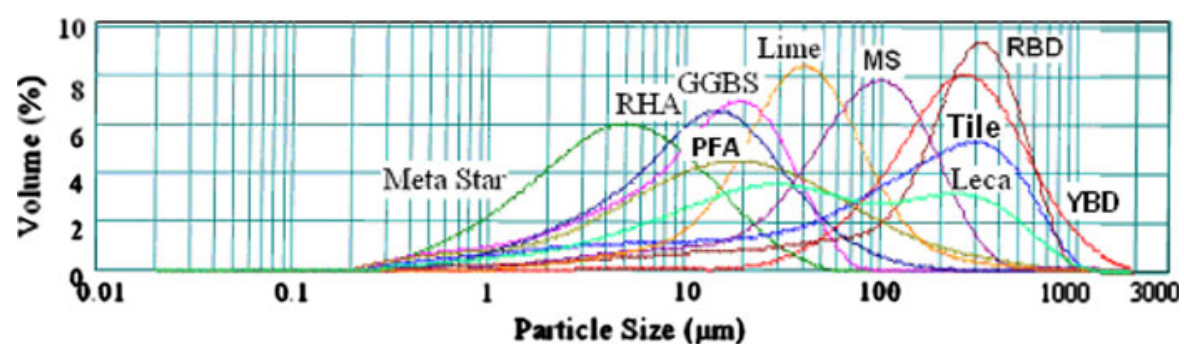



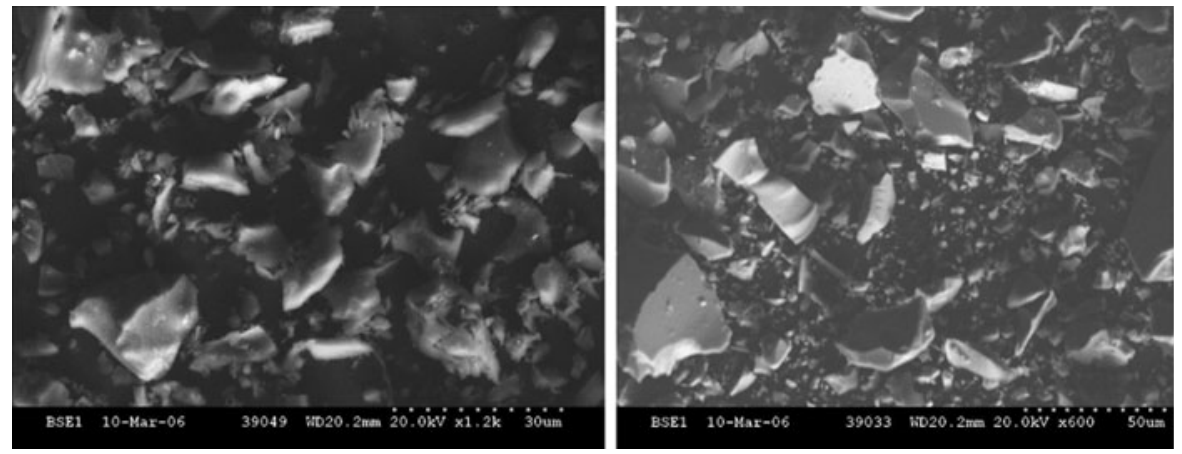

Fig. 2 SEM micrographs displaying the more planar and smoother character of the GGBS particles (right) when compared to those of RHA (left)

The chemical composition of the pozzolans is included in Table 2. According to these results, GGBS contains at least $75 \%$ more calcium than any other pozzolan. It is well known since early times that free lime content enhances pozzolan reactivity in PC composites: the hydraulic properties of the slags used for cement slag production increase with the amount of $\mathrm{CaO}$ in the slag [18]. However, in this research, the CL90s binder contributes high amounts of free lime to the paste, and therefore the calcium contained in the pozzolan may not determine reactivity.

Pozzolanic reaction is governed by the active silica and alumina contents and the specific surface of the pozzolan. A high specific surface makes lime combination easier. However, according to Massazza [8], this only applies to the earlier stages of the pozzolanic reaction whereas at longer ages, the pozzolanic reaction is mainly controlled by the active silica and alumina content. According to their $\mathrm{SiO}_{2}+\mathrm{Al}_{2} \mathrm{O}_{3}$ content, the pozzolans would rate, from more to less reactive, as follows: Metastar, RHA, MS, PFA, YBD, Leca, RBD, Tile, GGBS. These results refer to the total $\mathrm{SiO}_{2}+\mathrm{Al}_{2} \mathrm{O}_{3}$ content, however, a certain fraction may not be active therefore, the chemical composition cannot be investigated alone but it needs to take into consideration the mineralogy and amorphousness of the pozzolan which are included in Table 3. According to these results, the rate of amorphousness of the pozzolan was loosely categorised into four groups ranging from totally amorphous (displaying a large amorphous hump and no crystalline fraction in the XRD pattern) to slightly amorphous (very small amorphous hump).

As aforementioned, glassy pozzolans with only a limited amount of non-reactive crystalline minerals are considered very active, while pozzolans with a low glass content and a considerable amount of crystalline minerals are assumed to posses a weak activity. According to this, GGBS, Metastar, MS and RHA are the most reactive; followed by Leca and

Table 2 Chemical composition of the pozzolans

\begin{tabular}{|c|c|c|c|c|c|c|c|c|c|c|c|}
\hline Pozzolan & $\mathrm{SiO}_{2}$ & $\mathrm{Al}_{2} \mathrm{O}_{3}$ & $\mathrm{SiO}_{2}+\mathrm{Al}_{2} \mathrm{O}_{3}$ & $\mathrm{CaO}$ & $\mathrm{Fe}_{2} \mathrm{O}_{3}$ & $\mathrm{SO}_{3}$ & $\mathrm{TiO}_{2}$ & $\mathrm{MnO}$ & $\mathrm{K}_{2} \mathrm{O}$ & $\mathrm{MgO}$ & $\overline{\mathrm{P}_{2} \mathrm{O}_{5}}$ \\
\hline GGBS & 34.14 & 13.85 & 47.99 & 39.27 & 0.41 & 2.43 & 0.54 & 0.25 & 0.26 & 8.63 & - \\
\hline Leca & 52.78 & 24.39 & 77.17 & 3.59 & 11.42 & 0.39 & 0.88 & 0.37 & 2.82 & 2.70 & - \\
\hline Metastar & 51.37 & 45.26 & 96.63 & - & 0.52 & - & - & - & 2.13 & 0.55 & - \\
\hline MS & 92.10 & 2.13 & 94.23 & 1.10 & 1.62 & 0.28 & - & - & 1.32 & 1.05 & 0.23 \\
\hline PFA & 65.32 & 24.72 & 90.04 & 0.94 & 4.84 & 0.37 & 0.91 & - & 1.37 & 0.68 & 0.37 \\
\hline RBD & 48.24 & 22.15 & 70.39 & 10.31 & 6.67 & 6.94 & 0.91 & - & 2.97 & 1.17 & 0.26 \\
\hline RHA & 93.84 & 1.93 & 95.77 & 0.68 & 0.29 & - & - & 0.12 & 1.38 & 0.45 & 1.11 \\
\hline Tile & 46.61 & 21.47 & 68.08 & 11.34 & 7.19 & 7.62 & 0.96 & - & 3.05 & 1.12 & 0.20 \\
\hline YBD & 43.90 & 44.94 & 88.84 & 0.36 & 2.11 & - & 0.40 & - & 1.27 & 6.28 & 0.26 \\
\hline
\end{tabular}

- , Not detected 
Table 3 Mineralogical composition and rate of amorphousness of the pozzolans

\begin{tabular}{lll}
\hline Pozzolan & Rate of amorphousness & Mineralogical composition \\
\hline GGBS & (5) Totally amorphous & No crystalline fraction \\
Leca & (3) Intermediate & Quartz, wadsleyite, mullite and illite \\
Metastar & (4) Mostly amorphous & Quartz, tohdite, aluminum oxide, wollastonite and paragonite \\
MS & (4) Mostly amorphous & Quartz and cristobalite \\
PFA & (3-2) Intermediate to slightly & Quartz and mullite peaks \\
RBD & (2) Slightly amorphous & Quartz, hematite, anhydrite, gypsum, and anorthite \\
RHA & (4) Mostly amorphous & Quartz and cristobalite \\
Tile & (2) Slightly amorphous & Quartz, hematite, gismondine and gypsum \\
YBD & (2) Slightly amorphous & Mullite and cordierite \\
\hline
\end{tabular}

PFA. Finally, YBD, RBD and Tile are the weakest, less active pozzolans.

Despite the general assumption that the crystalline fraction of a pozzolan is either low-reactive or nonreactive, it has been evidenced that crystalline minerals can bind lime. Some zeolites have been found to be more reactive than volcanic glasses ([9] quoting Sersale et al.); and finely ground crystalline minerals such as alkali feldspar can also bind substantial amounts of lime ([8] quoting Malquori et al.). It has also been evidenced in lime mortars that crystalline minerals in fragments of greywacke, schist, shale and dolerite combine lime $[19,20]$. In addition, even the most advanced structural characterization techniques such as the X-ray diffraction system used, have difficulty in distinguishing between amorphous and very finely grained crystalline solids, due to the similarity of their interatomic distances: even amorphous materials have some short-range atomic order and, in very small crystals, a large fraction of the atoms are at or near the surface distorting atomic positions and decreasing structural order [21]. As a result of all the above, the amount of lime bound by the pozzolan's crystalline fraction may be underestimated. Therefore, this research investigated whether this amount was measurable, by contrasting the reactivity of the pozzolans with their mineralogical composition. The X-ray diffraction results evidenced that all pozzolans except for GGBS (which is totally amorphous) and MS and RHA (which are totally siliceous) contain a significant crystalline fraction consisting of silicoaluminates such as mullite- $3 \mathrm{Al}_{2} \mathrm{O}_{3}$ $2 \mathrm{SiO}_{2}$, cordierite- $(\mathrm{Mg}, \mathrm{Fe})_{2} \mathrm{Al}_{4} \mathrm{Si}_{5} \mathrm{O}_{18}$, illite- $\left(\mathrm{K}, \mathrm{H}_{3} \mathrm{O}\right)$ $(\mathrm{Al}, \mathrm{Mg}, \mathrm{Fe})_{2}(\mathrm{Si}, \mathrm{Al})_{4} \mathrm{O}_{10} \quad\left[(\mathrm{OH})_{2},\left(\mathrm{H}_{2} \mathrm{O}\right)\right]$, paragonite$\mathrm{NaAl}_{2}\left(\mathrm{Si}_{3} \mathrm{Al}\right) \mathrm{O}_{10}(\mathrm{OH})_{2}$, zeolite (gismondine) $-\mathrm{CaAl}_{2}$
$\mathrm{Si}_{2} \mathrm{O}_{8} \cdot 4\left(\mathrm{H}_{2} \mathrm{O}\right)$ and feldspar (anorthite) - $\mathrm{Ca} \mathrm{Al} \mathrm{Si}_{2} \mathrm{O}_{8}$ (see Table 3). Occasionally, the pozzolans also contain calcium/magnesium silicates such as wollastonite $\mathrm{Ca}$ $\mathrm{SiO}_{3}$ and wadsleyite $\beta$ - $\mathrm{Mg}_{2} \mathrm{SiO}_{4}$; Metastarllic oxides/ hydroxides (hematite $\mathrm{Fe}_{2} \mathrm{O}_{3}$, tohdite $5 \mathrm{Al}_{2} \mathrm{O}_{3} \cdot \mathrm{H}_{2} \mathrm{O}$ and aluminum oxide) and calcium sulphates (anhydrite and gypsum). These are reactive minerals, somewhat comparable to the calcium silicates and aluminate constituents of Portland cement clinkers, therefore, some of these can be binding a considerable amount of lime.

\subsection{Influence of physical properties of pozzolans on their water demand}

The results indicate that the water demand of the lime:pozzolan paste depends on the pozzolan's particle size and specific surface, and on the lime:pozzolan ratio. However, it was clearly evidenced that specific surface has a much greater influence on water demand than the particle size or the lime:pozzolan ratio.

According to the flow test, finer pozzolans have a greater water demand (Fig. 3). This agrees with the well known fact of finer particles requiring a greater amount of water to produce a given workability. In addition, as it can be seen from Fig. 3, there is a linear relationship between water demand and pozzolan content: the replacement of lime by pozzolan lowered the water demand of all pastes with the exception of Metastar. This is likely due to the greater water demand of the Metastar with respect to lime, on account of its high specific surface.

The influence of the specific surface of the pozzolan on the water demand of the paste is included in Fig. 4. As expected, a greater amount of 


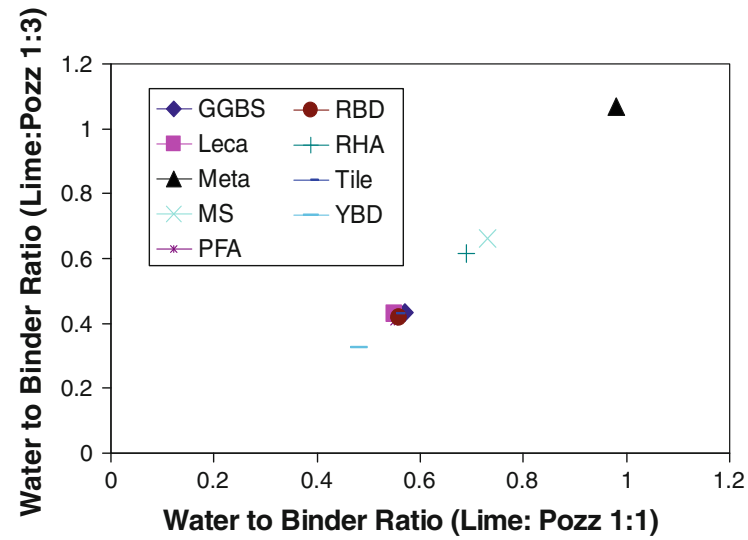

Fig. 3 Water demand of pozzolans in lime:pozzolan pastes of ratios $1: 3$ and $1: 1$

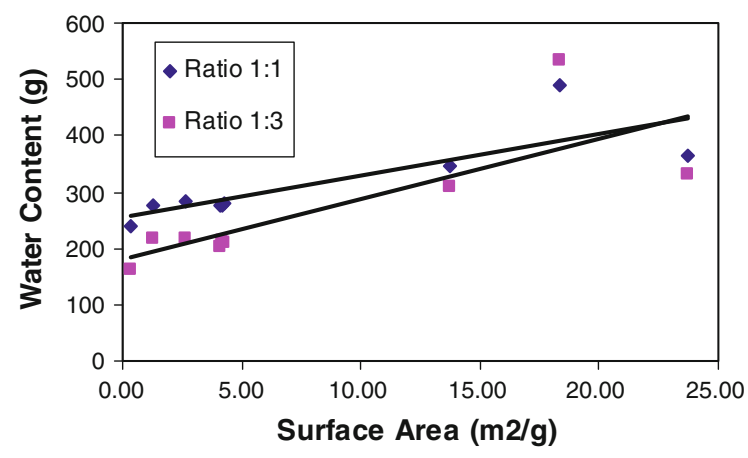

Fig. 4 Influence of pozzolan surface area and lime:pozzolan ratio on water demand

water was required by the pozzolans with a greater surface (Table 1); and specific surface had a much greater influence on water demand than particle size (RHA and GGBS have a similar particle size while RHA has a greater surface and a significantly higher water demand). Finally, the specific surface of the pozzolan has a much greater influence on the water demand of the paste than the amount of pozzolan in the mix; this is demonstrated by the bigger difference in water demand between the ratio $1: 1$ and 1:3 for a pozzolan of low surface area than for one of a higher surface area (Fig. 4).

It was also noted, that each pozzolan needed a specific amount of water in order to produce a given flow. An equation was formulated in order to calculate the specific water demand of each pozzolan (WDP) (Eq. 1). This was based on the water demand of the lime (water: lime ratio for the lime to flow $165 \mathrm{~mm}$ is 0.862 ), the amount of lime and pozzolan, and the total water content of the paste.
$\mathrm{WDP}=\frac{W-L \times \mathrm{WDL}}{P}$

where $W$ is the total amount of water in the mix $(\mathrm{g})$; $L$ amount of lime (g); $P$ amount of pozzolan $(\mathrm{g})$; and $\mathrm{WDL}=0.862 \mathrm{~g}$.

The WDP (expressed as grams of water per gram of pozzolan) was calculated according to Eq. 1 as an average of two ratios (1:1 and 1:3). The difference between the two ratios was typically under $10 \%$ except for the Leca and YBD. This was probably due to nonhomogenous character of these pozzolans, including a wide range of particle sizes. According to Eq. 1, GGBS has a water demand of $0.28 \mathrm{~g}$, Leca $0.27 \mathrm{~g}$, Metastar $1.1 \mathrm{~g}$, PFA $0.25 \mathrm{~g}$, RBD $0.26 \mathrm{~g}$, RHA $0.53 \mathrm{~g}$, Tile $0.26 \mathrm{~g}$ and YBD $0.12 \mathrm{~g}$. In order to validate the equation, 1:2 (lime:RHA) and 1:2 (lime:PFA) pastes were tested for flow using the water calculated with the equation. These produced flows of 162/165 and 165 respectively, thus validating the equation.

This equation applies to the pozzolans in this paper (with a given particle size and specific surface area) and, for example, if a brick dust with a greater specific surface area was used, it would require a higher water content to achieve a particular flow. However, once the water demand of a particular pozzolan has been determined, the equation allows to accurately predict water demand for a given flow when varying the lime:pozzolan proportions.

According to these results, the pozzolans were divided into two groups of high (Metastar, MS and RHA) and low (GGBS, Leca, PFA, RBD, Tile and YBD) water demand respectively.

\subsection{Early rate of pozzolanic reaction: speed of portlandite consumption}

As aforementioned, the progress of the pozzolanic reaction was investigated by recording new-formed minerals and changes in the relative amounts of portlandite and calcite in the XRD trace. However, no new-formed hydration products were detected, on an extended timescale, using XRD. This is possibly on account of their amorphous character or concealment by other mineral peaks. Despite the limitations of XRD to provide quantifiable results, it was decided to investigate the progress of the pozzolanic reaction by recording changes in the relative amounts of portlandite and calcite. 
Table 4 Reactivity of the pozzolans, analysed with mechanical, chemical and mineral methods

\begin{tabular}{|c|c|c|c|c|c|}
\hline \multirow[t]{3}{*}{ Pozzolan } & \multicolumn{4}{|l|}{ Activity index } & \multirow{3}{*}{$\begin{array}{l}\% \text { Portlandite } \\
\text { at } 6 \mathrm{~h}^{\mathrm{a}}\end{array}$} \\
\hline & \multirow{2}{*}{$\begin{array}{l}\text { Mechanical method } \\
\text { (strength ratio) }\end{array}$} & \multicolumn{3}{|c|}{ Chemical method (conductivity) } & \\
\hline & & Phase $1 \%$ drop & $\begin{array}{l}\text { Conductivity of } \\
\text { pozzolan in water }(\mathrm{mS})\end{array}$ & $\begin{array}{l}\text { Chemical } \\
\text { index }(S)\end{array}$ & \\
\hline GGBS & 29.5 & - & 0.09 & - & 0.0 \\
\hline Leca & 4.6 & - & 0.12 & - & 0.0 \\
\hline PFA & 3.4 & 3.4 & 1.10 & 0.95 & 12.9 \\
\hline Metastar & 38.1 & 9.8 & 0.01 & 9.75 & 0.0 \\
\hline MS & 12.5 & 4.3 & 0.64 & 2.08 & 9.4 \\
\hline RBD & 2.5 & 2.5 & 2.23 & 0.28 & 38.4 \\
\hline RHA & 12.0 & 6.8 & 0.13 & 1.81 & 0.0 \\
\hline Tile & 3.3 & 3.5 & 2.50 & 0.41 & 24.5 \\
\hline YBD & 1.2 & 3.9 & 0.03 & 0.55 & 39.9 \\
\hline
\end{tabular}

- , Not sensitive to this method

a $43.5 \%$ is the $\%$ of portlandite at $6 \mathrm{~h}$ in a pure lime sample

As the lime/pozzolan pastes cured, the portlandite was used in both carbonation (to form calcite) and in pozzolanic reactions (to form hydration products).

In order to estimate the amount of portlandite used for carbonation the consumption of portlandite in a pure lime sample was monitored (Table 4).

Therefore, the speed of consumption of portlandite (Table 4) corresponds to the early rate of pozzolanic reaction. The results can broadly separate the pozzolans into three groups. Within the first six hours GGBS, Metastar, Leca, and RHA have completely consumed the portlandite through carbonation and formation of hydration products. This period is extended to between 6 and $24 \mathrm{~h}$ for PFA and MS. The presence of portlandite after 3 days for the brick dusts suggests much slower reaction kinetics. As expected, a lime and lime/sand mix, which relies solely on carbonation, has a larger proportion of portlandite remaining after 7 days.

\subsection{Mechanical activity index}

The pozzolanic index measured by the mechanical method, expressed as the ratio of the compressive strength of the lime/pozzolan mix to a standard lime/ sand mix, is listed in Table 4. In all cases, the addition of the pozzolan increased the compressive strength of the lime mix measured after 28 days. Metastar and GGBS produced much higher mechanical activity indices than any of the other pozzolans; followed by the high-silica pozzolans RHA and MS (68\% reduction when compared to Metastar); and finally the PFA, Leca and the brick dusts with an index $89 \%$ lower than that of the Metastar pozzolan.

According to Massazza [8] the acceleration of the pozzolanic reaction positively affects strength development but the rate of strength increase depends on the type of pozzolan.

The results indicate that compressive strength and hence the mechanical activity index, is not only dependant on the amount of combined lime but also on the packing effect induced by the pozzolan and the microstructure of the hydration products formed. The results confirmed that reactivity, measured as strength development, increases with decreasing particle size (D90-90\% of the particles under this size) (Fig. 5). The well known physical filler effect of fine pozzolans, packing the space between large particles and thus increasing density, may be partially responsible for the high strength of the finer pozzolans GGBS, Metastar and RHA. MS probably benefits from the same effect, however, it has not been included in Fig. 5 as a result of the lack of laser data due to flocculation.

The pozzolans of higher water demand are those with the greater 28-day strength, therefore, the water demand of the pozzolan does not affect the compressive strength of the paste.

The compressive strength of the paste is also dependant on the type and microstructure of the hydration products formed [22], with silicate hydrates 


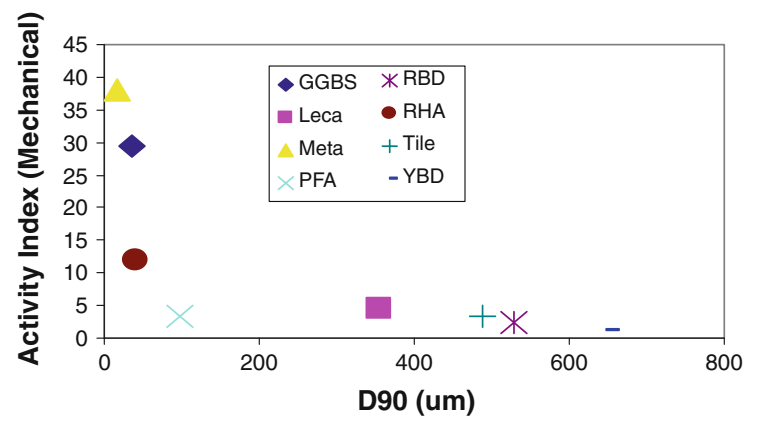

Fig. 5 Relationship between particle size and activity index (mechanical)

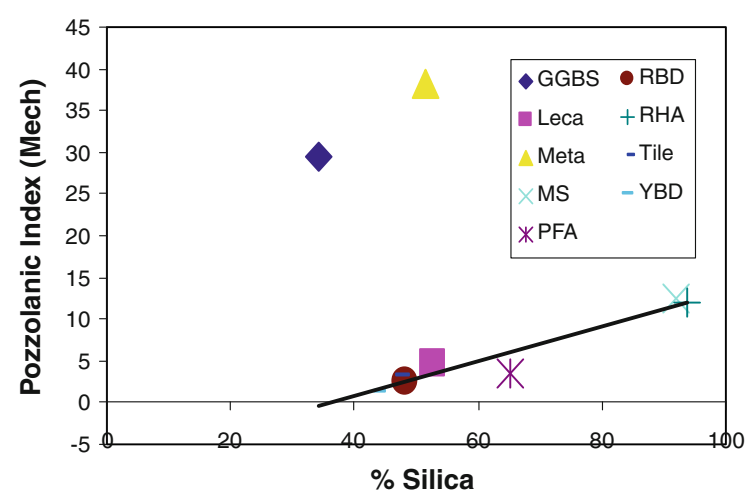

Fig. 6 Relationship between silica content and reactivity (mechanical index)

contributing more to strength than aluminate hydrates. The results evidenced that increasing silica content of the pozzolan results in higher mechanical indices (Fig. 6). However, there are two significant exceptions: GGBS and Metastar. The high strength of these two pozzolans can be ascribed to their physical filler effect (they are amongst the finest) and their chemical reactivity (Metastar has the highest chemical index while GGBS contains at least $75 \%$ more calcium than any other pozzolan). No hydraulic phases were determined in the GGBS by XRD, however, the limit of detection of this technique is $5 \%$. Therefore, the hydraulic character of the GGBS can be further contributing to the early strength of the paste.

The silica content above refers to both crystalline and amorphous silica. However, in order to be reactive, silica must be present in an amorphous form. A clear relationship between increasing amorphous content (Table 3) and increasing mechanical reactivity was established for the nine pozzolans (Fig. 7).

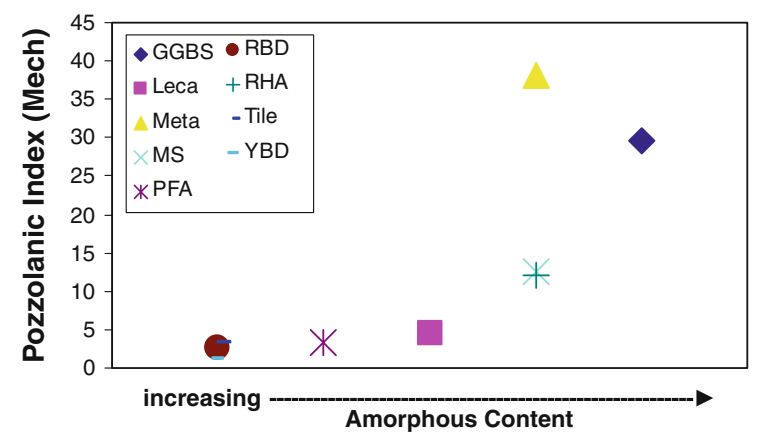

Fig. 7 Relationship between increasing amorphous content and reactivity (mechanical index)

\subsection{Chemical activity}

The chemical method, in which changes in conductivity of a lime/pozzolan solution were measured over time [23, 24], depicted four phases of activity similar to the four stages defined by McCarter and Tran [25]. The results are shown in Table 4 and Fig. 8.

During the first $3-5 \mathrm{~h}$ (phase 1), the conductivity reduced significantly by between 10 and $30 \%$. The rate of this decrease was typically between 3 and $10 \%$ per hour. According to phase 1, Metastar, RHA and MS are the most reactive. It could be argued for this initial conductivity to be overestimated as a result of the pozzolan's solubility and the presence of water soluble salts within the pozzolan. However, as it can be seen from Table 4 (conductivity of the pozzolans in water), this is not the case, on the contrary the most reactive pozzolans in phase 1 are amongst the least soluble. In relation to the presence of water soluble salts increasing conductivity measurements, as it can be seen from Table 2, tile and RBD are the pozzolans with the highest salt content however they are not amongst the most reactive.

Phase 1 was followed by a latent period (phase 2) where there was a gradual reduction in conductivity, the length of which depends on the reactivity of the pozzolan varying from approximately $20-90 \mathrm{~h}$, with a rate of decrease of less than $1 \%$ per hour. The latent period was followed by a significant drop in conductivity of between 40 and $70 \%$ (phase 3), at a drop-rate of over $1.5 \%$ per hour, extending over a period of approximately $20 \mathrm{~h}$. Following this rapid decrease, the reaction appears exhausted and a constant conductivity was maintained (phase 4). 


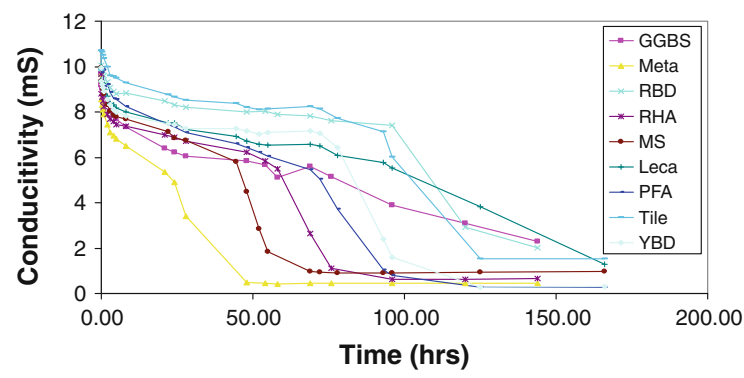

Fig. 8 Pozzolanic activity as change in conductivity over time (chemical activity index)

The rate of change of conductivity during phase 1 and the rate of change of conductivity over time for phases 1, 2 and 3 (included in Table 4 as chemical index) was used to quantify the rate of pozzolanic activity of the material [25]. Both the phase 1 drop and the chemical index evidenced that the Metastar, RHA and MS are the most reactive.

GGBS and Leca do not have a distinct phase 2 or 3 and their conductivity continuously decreases over time therefore, their reactivity cannot be determined using this method. However, their \% drop in conductivity rate over time during phase 1 was: $5.6 \%$ at $3 \mathrm{~h}, 4.7 \%$ at $4 \mathrm{~h}, 4.1 \%$ at $5 \mathrm{~h}$ for GGBS; and $5.3 \%$ at $3 \mathrm{~h}, 4.2 \%$ at $4 \mathrm{~h}, 3.6 \%$ at $5 \mathrm{~h}$ for Leca. According to this, they are amongst the most reactive, falling between Metastar, and RHA. Therefore, according to this method, the most reactive pozzolans (in order of decreasing reactivity) are Metastar; GGBS and Leca; RHA and MS.

The results above suggest that, for the first hours of the pozzolanic reaction in suspension (phase 1), the dominant factor that determines pozzolanic activity is amorphousness followed by specific surface: Metastar and RHA are the pozzolans with a greater ability for lime fixation while MS, with the greatest surface area and $\mathrm{SiO}_{2}$ content, shows approximately half of the binding lime capacity. This disagrees with previous authors stating that reactive $\mathrm{SiO}_{2}$ and specific surface are the dominant factors that determine initial reactivity [26].

\subsection{Pozzolan reactivity according to activity indices and portlandite consumption}

The percentage of lime combined by different pozzolans varies within wide limits, and depends on factors related to the nature of the pozzolan (chemical and mineral composition and specific surface area) and the mix characteristics (conditions within which the pozzolanic reaction occurs) [17]. This means that accurately deducing a pozzolan's reactivity is complex and dependant on the methodology, therefore, in this research, the reactivity was determined using the three methods above (Table 4) and the results later contrasted with the setting time of the paste.

From the activity indices and consumption of portlandite (Table 4, Fig. 8), it is apparent that Metastar, GGBS, RHA and MS are the most reactive. Although not sensitive to the chemical index, GGBS has a mechanical index comparable to that of Metastar, much higher than any of the other pozzolans. In addition, it consumes portlandite in the first $6 \mathrm{~h}$, therefore, it can be considered one of the most reactive pozzolans. These four most reactive pozzolans are either totally (GGBS) or mostly amorphous (Metastar, RHA and MS). In addition, Metastar, RHA and MS have a specific surface much higher than any of the other pozzolans, while GGBS has a lower specific surface but it is amongst the finest. This indicates that specific surface and amorphousness are important variables affecting reactivity (measured as strength development). In contrast, the silica content of the pozzolan affects the strength development of the paste to a lesser extent: GGBS and Metastar have nearly half the $\mathrm{SiO}_{2}$ content of MS and RHA and yet approximately three times their strength.

\section{Conclusion}

This paper concludes that amorphousness determines pozzolan reactivity to a much greater extent than any other pozzolan property. It also concludes that the specific surface area of the pozzolan governs the water demand of the paste, while amorphousness determines the strength of the paste. In contrast, the chemical composition of the pozzolan is not instrumental as a variable affecting neither pozzolan reactivity nor strength.

The results evidenced that (except Metastar) the replacement of lime by pozzolan lowers the water demand of the paste. The flow test clearly subdivided the pozzolans into two groups of high (Metastar, MS and RHA) and low water demand (GGBS, Leca, PFA, RBD, Tile and YBD); and evidenced that the pozzolan's specific surface has a much greater 
influence on water demand than its particle size, amorphousness or the amount of pozzolan in the mix.

Metastar and GGBS pozzolans produce pastes of higher strength than any of the other pozzolans; these are followed by the high-silica pozzolans RHA and MS (68\% reduction); and finally the PFA, Leca and the brick dusts with a mechanical index $89 \%$ lower than that of Metastar. The results indicate that the compressive strength of the paste depends on the amount of lime combined by the pozzolan; the type of hydration products formed; and the physical filler effect induced by the pozzolan. However, strength is mainly determined by the amorphousness and particle size of the pozzolan: a clear relationship between increasing amorphousness and increasing strength was established for all pozzolans, and it was confirmed that strength rose with decreasing pozzolan's particle size. The paper concludes that amorphousness, particle size and specific surface affect the strength development of the paste in a greater extent than the silica content of the pozzolan.

Rather than the pozzolan's reactivity, the mechanical index measures the strength of the paste, which not only relates to the early evolution of the pozzolanic reaction (amount of combined lime and hydrates formed), but also to physical factors that impact the density of the paste such as grain packing and composition and microstructure of the hydration products formed in the pozzolanic reaction. Despite this, there is a good correlation between the chemical and the physical activity indices. From these indices and the rate of portlandite consumption, it is apparent that the most amorphous pozzolans (Metastar, GGBS, RHA and MS) are the most active.

From the chemical index, the paper also concludes that the dominant factor that determines the initial activity of a pozzolan in suspension is amorphousness rather than $\mathrm{SiO}_{2}$ content or specific surface.

It appears from the results that the amount of lime combined by reactive crystalline phases in the pozzolans is insignificant when compared to that bound by their amorphous fraction.

The behaviour and properties lime/pozzolan pastes are determined by complex relationships of interdependent variables including pozzolan surface area, particle size, chemical composition and amorphousness. These govern water demand and affect mechanical properties and reactivity.
Acknowledgments The authors wish to thank the Environmental Protection Agency for funding this research. The authors also thank the Traditional Lime Company, Clogrennane Lime, Larsen Building Products and Ecocem for the provision of materials and Mr. Neal Leddy and Mr. Colin Reid (Centre for Microscopy and Analysis); Dr. Robbie Goodhue (Geology Department) and Ms. ElaineTreacy (Geography Department), Trinity College, for their help with the SEM/EDXRA, XRD and laser equipment respectively.

\section{References}

1. Caijun S (2001) Studies on several factors affecting hydration and properties of lime-pozzolan cements. J Mater Civ Eng 13(6):441-445

2. Carr JG (1995) An investigation on the effect of brick dust on lime-based mortars. Masters dissertation, University of Pennsylvania

3. Moropoulou A, Carmak A, Labropoulos KC, Van Grieken R, Torfs K (2004) Accelerated microstructural evolution of a calcium-silicate-hydrate $(\mathrm{C}-\mathrm{S}-\mathrm{H})$ phase in pozzolanic pastes using fine siliceous sources: Comparison with historic pozzolanic mortars. Cem Concr Res 34(1):1-6

4. Hicky Morgan M (1914) Vitruvius: the ten books on architecture. Harvard University Press, Cambridge

5. Hooper WD, Ash HB (1939) Marcus Porcius Cato and Marcus Terentius Varro, De Re Rustica. William Heinemann Ltd, Harvard University Press, London

6. Plommer H (1973) Faventinus, Vitruvius and later roman building manuals. Cambridge University Press, London

7. Pavía S, Caro S (2008) An investigation of Roman mortar technology through the petrographic analysis of archaeological material. Constr Build Mater 22(8):1807-1811

8. Massazza F (2007) Pozzolana and pozzolanic cements. In: Hewlett PC (ed) Lea's chemistry of cement and concrete, 4th edn. Elsevier, UK, pp 471-602

9. Massazza F (2002) Properties and applications of natural pozzolans. In: Bensted J, Barnes JP (eds) Structure and performance of cements. Spon Press, London

10. Costigan A, Pavía S (2010) Mechanical properties of clay brick masonry bound with hydraulic limes and hydrated calcium lime. In: Jäger W, Haseltine B, Fried A (eds) 8th International masonry conference, Dresden, pp 903-914

11. Hanley R, Pavía S (2008) A study of the workability of natural hydraulic lime mortars and its influence on strength. Mater Struct 41(2):373-381. doi:10.1617/s11527007-9250-0

12. Pavía S, Hanley R (2010) Flexural bond strength of natural hydraulic lime mortar and clay brick. Mater Struct 43(7):913-922. doi:10.1617/s11527-009-9555-2

13. EN 459-1 (2001) Building lime. Part 1: Definitions, specifications and conforming criteria. European Committee for Standardisation CEN, Brussels

14. Bish DL, Post JE (1988) Modern powder diffractionreviews in mineralogy. J Appl Crystallogr 21:86-91

15. Mostafaa NY, El-Hemalyb SAS, Al-Wakeelc EI, ElKorashyc SA, Browna PW (2001) Characterization and evaluation of the pozzolanic activity of Egyptian industrial 
by-products I: silica fume and dealuminated kaolin. Cem Concr Res 31(3):467-474

16. EN 450-1 (2005) Fly ash for concrete. Part 1: Definition, specifications and conformity criteria. European Committee for Standardisation CEN, Brussels

17. EN 459-2 (2002) Building lime. Part 2: Test methods. European Committee for Standardisation CEN, Brussels

18. Eckel E (1905) Cements, limes and plasters, 1st edn. Wiley, New York

19. Pavía S (2008) A petrographic study of the technology of hydraulic mortars at masonry bridges, harbours and mill ponds. In: Cannon E, West R, Fanning P (ed) Concrete research and bridge infrastructure symposium, Galway. Galileo Editions, pp 253-264

20. Pavía S (2008) A petrographic study of mortar hydraulicity. In: HMC08, Mortars: characterization, diagnosis, conservation, repair and compatibility. LNEC, Laboratorio General Engenharia Civil, Lisbon
21. Varshneya A (1994) Fundamentals of inorganic glasses. Academic Press, Boston

22. Taylor FW (1997) Cement chemistry. Thomas Telford, London

23. Luxan MP, Madruga F, Saavedra J (1989) Rapid evaluation of pozzolanic activity of natural products by conductivity measurement. Cem Concr Res 19:63-68

24. Paya J, Borrachero MV, Monzo J, Peris-Mora E, Amahjour F (2001) Enhanced conductivity measurement techniques for evaluation of fly ash pozzolanic activity. Cem Concr Res 31(1):41-49

25. McCarter WJ, Tran D (1996) Monitoring pozzolanic activity by direct activation with calcium hydroxide. Constr Build Mater 10(3):179-184

26. Uzal B, Turanh L, Yucel H, Goncuoglu A, Culfaz A (2010) Pozzolanic activity of clinoptilolite: a comparative study with silica fume, fly ash and a non-zeolitic natural pozzolan. Cem Concr Res 40(3):398-404 